\title{
ANALISI KO-TEKSTUAL DALAM AUDIO VISUAL BAGIAN TEATER TRADISI TARLING DRAMA BARIDIN KARYA H.ABDUL AJIB PRODUKSI KURNIA NADA GROUP
}

\author{
Waro'ah \\ Institut Seni Indonesia Yogyakarta
}

\begin{abstract}
Abstrak: Tarling drama Baridin adalah pertunjukan teater tradisi asal Cirebon yang ide ceritanya bermula dari mitos kemat Jaran Guyang. Berlatar belakang permasalahan kesenjangan sosial antara dua keluarga membuat Baridin melakukan kemat Jaran Guyang sebagai akibat dari sakit hati karna telah dihina dan cinta ditolak. Penelitian analisis ko-tekstual tarling drama Baridin bertujuan memaparkan aspek-aspek tarling drama Baridin sebagai teater tradisi secara instrinsik. Hasil dari penelitian ini adalah mengetahui dialog, alur, penokohan, latar dan tema pertunjukan tarling drama Baridin, serta mengetahui makna syair kemat Jaran Guyang dilihat dari arti denotatif dan konotatif yang menjadi mitos sekaligus pesan moral bahwa janganlah menghina dan berbuat kasar pada orang lain.
\end{abstract}

Kata kunci: tarling, drama, analisis ko-tekstual, mitos

\begin{abstract}
Tarling drama Baridin is a traditional theater show from Cirebon whose story idea stems from the myth of kemat Jaran Guyang. Background of social disparity between two families makes Baridin performing Jaran Guyang's death as a result of heartache because he has been insulted and love is rejected. The research of co-textual analysis of Baridin drama tarling aims to explain the aspects of Tarling drama Baridin as a theater tradition intrinsically. The result of this research is to know the dialogue, plot, characterization, background and theme of Bariar drama tarling show, and to know the meaning of the dashed verse of Jaran guyang seen from the denotative and connotative meaning which become the myth as well as the message that do not insult and do rude to others.
\end{abstract}

Keywords: tarling, drama, co-textual analysis, myth

\section{Pendahuluan}

Tarling pada mulanya dikenalkan oleh seniman musik bernama Sugra. Sugra mentransformasikan nada-nada pentatonis gamelan ke dawai-dawai gitar yang bernada diatonis untuk mengiringi tembang-tembang (kiser) Dermayonan dan Cirebonan yang merupakan tembang tarling. Selanjutnya, Sugra merupakan tokoh tarling Indramayu memasukan unsur drama pada tarling dengan lakon yang berkisah kehidupan sehari-hari yang terjadi pada masyarakat Indramayu. Lakon-lakon yang terkenal pada masa itu seperti Saedah-Saenih, Pegat Balen, dan Lair Batin (Sunaryo, 2016).
Jenis kesenian gitar seruling belum dinamakan Tarling. Sugra sebagai seniman asal Indramayu menamakan dengan Melodi Kota Darma Ayu (MKDA), di Cirebon bernama Melodi Kota Udang (MKU), dan di Majalengka dikenal dengan nama Melodi Kota Resik (MKR). Pada tahun 1962, ketua Badan Pemerintah Harian (BPH, sekarang DPRD) kabupaten Cirebon menamakan kesenian menggunakan gitar dan seruling sebagai Tarling. Tarling mempunyai filosofi yen wis mlatar kudu eling (kalau merasa bersalah, harus segera bertaubat). Meskipun orang pertama yang memperkenalkan tarling berasal dari seniman Indramayu, namun 
menurut budayawan Cirebon TD. Sudjana menyatakan bahwa tarling adalah milik masyarakat Cirebon, ini dapat dibuktikan dengan melacak asal-usul bebunyian yang diciptakan yakni berasal dari musik gamelan sekaten yang tersimpan di keraton Kesepuhan Cirebon. Cirebon, Indramayu, dan Majalengka merupakan daerah keresidenan yang pusat kegiatan dan pemerintahannya di wilayah Cirebon. Masyarakat sekitar Cirebon yakni Indramayu, Majalengka maupun Kuningan bisa melakukan kegiatan yang sama-sama atau menyerupai tanpa saling mengklaim itu adalah hasil dari cipta mereka (Sunaryo, 2016)

Tarling di Cirebon umumnya mengangkat cerita berupa kisah legenda atau mitos yang ada di Cirebon, diiringi lagu tarling kiser Cirebonan, dan bahasa dalam drama dan tembangnya menggunakan bahasa Cirebon. Bahasa Cirebon merupakan percampuran antara bahasa Sunda dan Jawa. Cirebon merupakan kota dan kabupaten keresidenan provinsi Jawa Barat yang letak geografisnya berbatasan dengan provinsi Jawa Tengah. Letak geografis yang seperti itu sangat berpengaruh terhadap pertumbuhan dan perkembangan bahasa pergaulan sehari-hari. Hal ini terlihat, baik dalam bahasa pergaulan maupun dalam bahasa pengantar pendidikan di pesantrenpesantren mempergunakan bahasa Jawa yang berkembang di lingkungan para pemakai bahasa Sunda, sehingga menimbulkan masyarakat dwi-bahasa. Bahasa pada tarling Cirebon memiliki ciri tersendiri dan bersifat khas dari bahasa pada tarling Indramayu maupun Majalengka. Selain bahasa yang khas, tarling Cirebon juga pada umumnya mengangkat cerita yang bersumber dari mitos, dan mitos yang berkembang di Cirebon tentu memliki nilai budaya tersendiri. Mitos yang berkembang di Cirebon dipengaruhi oleh keadaan sosial maupun geografisnya.
Mitos mempengaruhi kesenian tradisi tarling pada bagian drama Baridin berupa jawokan (Noer, 2015). Cerita Baridin merupakan mitos yang berkembang di masyarakat Cirebon. Masyarakat Cirebon bahkan sering mengisahkan cerita Baridin secara turun temurun, harapannya bisa menjadi teladan atau wejangan pemudapemudi untuk bersikap sopan dan santun, tidak kasar apalagi kepada orang tua.

Pertunjukan teater tradisi tarling merupakan serangkaian pertunjukan yang melibatkan musik, lagu, tarian, lawakan, dan drama. Pada bagian awal pertunjukan tarling disuguhkan dengan musik tetalu, yakni musik tarling yang menggunakan instrumen gamelan, gitar dan seruling tanpa diiringi lagu atau kidung, berikutnya adalah pertunjukan lagu-lagu tarling Cirebonan, selanjutnya ada pertunjukan tarian yakni tari bendrongan dan sebelum ke pertunjukan drama klasik disuguhkan drama lawakan yang durasinya kurang lebih 20-30 menit, baru setelah itu disajikan drama klasik yang durasinya bisa sampai 2 jam. Salah satu drama klasik yang populer pada teater tradisi tarling adalah drama Baridin karya $\mathrm{H}$. Abdul Ajib.

Tarling drama Baridin karya $\mathrm{H}$. Abdul Ajib menceritakan kisah romantik Baridin dan Suratminah yang berakhir tragedi. Baridin jatuh cinta pada seorang gadis cantik jelita anak juragan sawah bernama Suratminah, lalu ibu Baridin yang bernama mbok Wangsih diminta Baridin untuk melamar Suratminah. Cinta Baridin ditolak mentah-mentah oleh Suratminah, mbok Wangsih diusir kasar oleh Suratminah dan ayahnya yang bernama bapak Dam. Baridin tidak terima hinaan Suratminah, ia akhirnya mengemat Suratminah dengan ajian kemat Jaran Guyang. Kemat Jaran Guyang membuat Suratminah gila dan tergila-gila pada Baridin, namun Baridin sudah dendam atas sakit hati dan ingin Suratminah merasakan bagaimana cintanya juga ditolak. 
Di akhir cerita, Suratminah meninggal dan disusul Baridin yang juga meninggal ditempat yang sama yakni di sawah.

\section{Landasan Teori}

Penelitian tarling drama Baridin ini menggunakan teori analisis ko-tekstual dari Marco de Marinis. Analisis ko-tekstual memusatkan pada keteraturan-keteratuan "internal" teks pertunjukan dengan sifat-sifat material dan formalnya (antara lain heterogenitas atau keberagaman ekspresifnya, multifitas atau banyaknya kode-kode, durasi yang pendek, atau sifat yang tidak bisa diulang) dan level-level struktur tekstual (kode - kode dan struktur tekstual), (Marinis, 1993).

Struktur merupakan cara pengolahan unsur-unsur untuk mencapai efek estetis pada sebuah karya sastra (Welek, 2014). Struktur mencangkup bentuk dan isi, sejauh mempunyai fungsi estetis. Struktur teater adalah teks yang terdiri dari tekstur, rangkaian, anyaman berbagai laku. Struktur teater berupa rangkaian peristiwa dramatik yang tersusun dari unsur dialog, alur, penokohan, latar, dan tema. Teater sebagai teks berarti merupakan sebuah rangkaian yang terbantu atas keberagaman unsur-unsur yang saling berelasi. (Barba,1991).

\section{Hasil dan Pembahasan}

\section{Tema}

Tema merupakan dasar atau pokok dalam peristiwa yang dipersoalkan atau dipermasalahkan serta dicari jawabannya (Satoto, 2012) Tema mampu memberikan kekuatan dan kesatuan kepada peristiwaperistiwa yang diterangkan dan menceritakan sesuatu kepada seseorang tentang kehidupan pada umumnya. Tema pada tarling drama Baridin karya H. Abdul Ajib dapat dilihat dari kesatuan atas peristiwa-peristiwa konflik yang terjadi antara Suratminah dan Baridin, serta akibat dari konflik yang terjadi antar kedua tokoh tersebut yakni, dendam atas cinta yang ditolak.

\section{Dialog}

Dialog merupakan unsur penting pada drama. Tanpa dialog, maka tidak bisa disebut karya drama. Dialog yang diucapkan tokoh dapat untuk menetapkan karakter tokoh, ruang dan lakuan. Dialog dalam teater daerah pada dasarnya dapat dibedakan menjadi dua yakni; pertama, dialog dalam bentuk bahasa prosa, dan kedua, dialog dalam bentuk bahasa puisi yang dilagukan. (Bandem \& Sal Murgiyanto, 1999). Dialog pada tarling drama Baridin sangat beragam, ada yang berupa dialog narasi tanpa dilagukan, dialog tembang parikan dan wangsalan yang merupakan ciri dari teater tradisi, serta dialog kidung.

Alur

Alur merupakan rangkaian peristiwa yang dijalin berdasarkan hubungan sebab akibat dan merupakan pola kaitan yang menggerakan jalan cerita ke arah pertikaian dan penyelesaian (Sahid, 2012). Alur tarling dramaBaridin karya H. Abdul Ajib produksi Kurnia Nada memiliki rangkaian cerita yang saling bersinambung dan simultan pada alur yang berbentuk segitiga Aristotelian yakni adanya Protatis,Epitasio, Catastasis, dan Catastrophedalam kesatuan waktu, dan kesatuan kejadian atau kesatuan idesebagai berikut:

Protatis, merupakan permulaan atau bagian awal naskah yang menjelaskan peran dan motif lakon. Drama Baridin dibuka dengan munculnya tokoh sentral Suratminah dan Baridin yang diiringi musik tarling. Gerakan Baridin memutari Suratminah sambil membawa kayu yang diimajinasikan sebagai weluku serta sarung yang disampirkan dibahu, lalu terjadi dialog narasi antara keduanya mengenai maksud Baridin menanyakan letak sawah Abu Nawas pada Suratminah, namun kedua tokoh tersebut malah saling memuji dan mengejek. Baridin 
sudah tertarik dengan Suratminah, ia memuji kecantikan Suratminah, sementara Suratminah malah mengejek Baridin dengan mengatakan "weh, wong pan meluku jeh bolak-balik ning kene bae. Mana meluku ning sawah" (weh, orang mau membajak kok bolak-balik di sini saja. Sana membajak sawah). Sambil menyanyikan lagu Temon, kedua tokoh tersebut malah semakin mengejek, memaki, memuji.

Epitasio, merupakan jalinan kejadian yang berisi konflik antar tokoh. Konflik tarling drama Baridin ditandai pada adegan ketiga dengan peristiwa munculnya tokoh mbok Wangsih menyanyikan tembang megatruh yakni tembang kesedihan, duka nestapa, lalu konflik semakin memuncak pada adegan keenamketika mbok Wangsih melamar Suratminah dengan membawa secengkeh pisang dan uang receh, sontak ia dihina Suratminah.

Catastasis, merupakan puncak laku atau klimaks peristiwa, peristiwa mencapai titik akulminasinya atau titik puncak dramatik. Klimaks alur tarling drama Baridin ditandai pada adegan kesepuluh, yakni peristiwa Baridin melapalkan kemat Jaran guyang pada Suratminah.

Catastrophe, merupakan penutupan dari rangkaian peristiwa dramatik. Adegan kelima belas menandai peristiwa catastrophe yakni kedua tokoh utama yang terlibat konflik dari awal bagian pertunjukan meninggal pada tempat yang sama di sawah. Suratminah akhirnya menemukan Baridin, ia terlihat senang ketika bertemu Baridin. Disapanya Baridin oleh Suratminah, namun Baridin malah berpaling dan bersikap ketus. Melihat Baridin seperti itu, Suratminah langsung mendekati Baridin dan meminta maaf atas perlakuannya yang menghina mbok Wangsih dan Baridin, tapi Baridin masih bersikap dingin. Rupanya sakit hati Baridin tidak mudah diobati dengan permohonan maaf Suratminah. Baridin terlanjur dendam, karena baginya sakit hati mbok Wangsih jauh lebih melukai hatinya. Dendam Baridin harus dituntaskan, Suratminah harus turut merasakan kepedihan hatinya, dan untuk bisa tuntas Baridin tidak bisa mengampuni Suratminah

\section{Penokohan}

Penokohan biasanya dipakai dalam dua konteks. Konteks pertama, penokohan menunjuk pada individu-individu yang muncul dalam cerita. Konteks kedua, penokohan merujuk pada percampuran dari berbagai kepentingan, keinginan, emosi, dan prinsip moral dari individu-individu tersebut. (Stanton, 1965). Pada cerita drama dapat ditemukan satu tokoh utama atau tokoh sentral yaitu tokoh yang terkait dengan semua peristiwa yang berlangsung dalam cerita, dan tokoh tambahan atau tokoh periferal (Sayuti, 2000).

Penokohan dalam konteks pertama pada tarling drama Baridin karya H. Abdul Ajib adalah tokoh Baridin, Suratminah, mbok Wangsih, bapak Dam, Gemblung, Gandul, teman-teman Suratminah, para pelamar, dan tetangga bapak Dam. Namun untuk bisa diperjelas, beberapa tokoh yang disebutkan dibagi menjadi tokoh utama dan tokoh tambahan. Tokoh utama yang terkait dengan semua peristiwa dalam cerita tarling drama Baridin karya H. Abdul Ajibadalah tokoh Baridin.

Penokohan dalam konteks kedua adalah penokohan yang merujuk pada percampuran dari berbagai kepentingan, keinginan, emosi, dan prinsip moral dari tokoh sentral maupun tokoh periferal. Tokoh periferal ini adalah Suratminah, mbok Wangsih, bapak Dam, tukang palak, dan Gemblung.

Berikut penggambaran penokohan dari tokoh sentral Baridin dan tokoh periferal yakni, Suratminah, bapak Dam, mbok Wangsih, Gemblung, dan tukang palak.

Tokoh Baridin

Sebagai tokoh sentral, tokoh Baridin memiliki peran penting dalam serangkaian 
peristiwa dramatik disepanjang adegan tarling drama Baridin. Berikut gambaran penokohan tokoh Baridin ketika berdialog dengan Suratminah pada adegan pertama.

1. BARIDIN:

Lagi enak-enak tungkul mlaku, ana bocah wadon ngomong kaku. Diarani bocah ganjen ora ngaku, nyangka isun wong adol weluku. Yen isun iku aran Baridin, urip lagi menderita batin, saben dina lagi nyandang isin, sebab durung ngalami kawin

(Sedang enak-enak jalan, ada perempuan bicara lucu. Dibilang perempuan centil tidak mau, disangka aku orang jualan bajak. Kalau aku bernama Baridin, hidup sedang menderita batin, tiap hari menanggung malu, sebab belum merasakan kawin)

Percakapan tersebut adalah dialog Baridin saat pertama kali bertemu dengan Suratminah, seorang perempuan cantik yang kaya. Diawal pertemuan itu, Baridin sudah memperkenalkan dirinya bernama Baridin, ia juga terlihat tertarik dengan Suratminah namun dengan sikap merendah diri karena keadaan dirinya yang seorang tukang weluku. Baridin juga mengungkapkan dirinya yang malu karena diusianya ia belum menikah. Dari gambaran tersebut, usia tokoh Baridin bisa diperkirakan sekitar 30an tahun, karena diusia tersebut terutama di desa, orang merasa malu jika belum menikah.

Tokoh Suratminah

Tokoh Suratminah merupakan tokoh periferal yang memegang peran penting sebagai tokoh pembanding dari tokoh sentral, karena dirinya terlibat langsung dari konflik sampai klimaks dengan tokoh Baridin.

Kostum yang dipakai Suratminah begitu glamour, dengan dress warna hitam dihias manik-manik berlian dan emas. Dari kostum itu tergambar status sosial Suratminah adalah orang kaya. Sementara dialog yang diucapkan Suratminah menggambarkan ia adalah seorang yang sombong, angkuh dan mudah mengejek orang lain.

Tokoh Bapak Dam

Penokohan tokoh bapak Dam dapat digambarkan dari tindakan, ucapan tokoh yang dekat dengannya yakni tokoh Suratminah. Percakapan bapak Dam dengan Suratminah terlihat akrab menggambarkan sosok ayah dan anaknya. Gambaran tersebut diperkuat ketika Suratminah memanggil bapak Dam dengan sebutan $M a$, dimana sebutan itu dalam bahasa Cirebon berarti ayah atau bapak. Selain itu, dari dialog tersebut tampak bahwa bapak Dam adalah sosok penyayang dan perhatian pada anaknya. Namun, hal berbeda terjadi ketika tokoh bapak Dam berdialog dengan mbok Wangsih. Bapak Dam terlihat sebagai sosok yang sombong, angkuh, serta bersikap kasar pada oranglain.

Tokoh Mbok Wangsih

Penokohan tokoh mbok Wangsih dapat tergambarkan ketika dirinya bermonolog menembangkan tembang megatruh. Tembang mbok Wangsih menunjukan latar belakang sosial mbok Wangsih adalah seorang janda yang memiliki anak bernama Baridin, serta umurnya sekitar 50an. Pada monolog tersebut juga menggambarkan sifat keibuan dan penyayang mbok Wangsih pada anaknya. Terlihat juga strata sosial tokoh mbok Wangsih dari pakaiannya yang compangcamping dan banyak tambalannya adalah orang dari kalangan bawah.

Tokoh Gemblung

Tokoh Gemblung adalah salah satu tokoh periferal yang kelihatannya tidak terlalu penting disetiap adegannya, namun tokoh ini menjadi jembatan atas tindakan yang diambil tokoh sentral, karena jika tidak ada tokoh Gemblung bisa dimungkinkan peristiwa yang hadir akan berbeda. Penokohan tokoh Gemblung adalah seorang yang memberikan ajian kemat Jaran Guyang pada Baridin, hubungan Gemblung dan 
Baridin juga tersirat sebagai hubungan sahabat karib, dimana hanya sahabat karib yang mau menolong sahabatnya yang sedang kesusahan, demikian juga yang terjadi antara Gemblung dan Baridin. Dilihat dari pakaian Gemblung memakai baju batik dan blankon dapat disiratkan strata sosial Gemblung adalah kelas menengah kebawah.

Tokoh tukang palak

Sama seperti tokoh Gemblung, tokoh tukang palak juga tidak mengambil peran yang begitu signifikan di setiap adegannya, namun tokoh tukang palak memberikan gambaran ironi teater tik, yakni tokoh yang secara magis mampu meramalkan kejadian yang akan datang. Gambara ironi teater tik inilah yang mendasari alur pada pertunjukan tarling drama Baridin, karena menjadi dasar sebagai mitos yang membangun peristiwa kemat jaran guyang.Berikut sequen gambar penokohan tokoh tukang palak ketika meramal kejadian yang akan mendatang.

Penokohan tokoh tukang palak jelas tersirat dari sequen gambar tersebut adalah seorang peramal dengan latar belakang sosial dari kelas bawah. Hal ini ditunjukan pada peristiwa ketika bapak Dam memanggil tukang palak yang kebetulan lewat didepan rumahnya. Profesi tukang palak adalah hal yang umum ada di daerah pedalaman atau di pinggiran pantai, karena masyarakat tersebut dinilai lugu dan masih percaya dengan halhal magis. Masyarakat tersebut juga mampu menilai mana tukang palak yang mahir, yang dalam hal demikian adalah orang yang dipercaya benar-benar mempunyai ilmu magis seperti ilmu kanuragan, dan tukang palak abal-abal atau murahan, yang biasanya kerjanya keliling mencari pelanggan atau biasa mangkal di acara-acara upacara adat seperti upacara Muludan. Tukang palak disini adalah seorang yang umumnya dibayar murah, karena dia berkeliling dan menghampiri pelanggan, maka dari itu secara ekonomi dia tergolong orang miskin.

\section{Latar}

Sebuah karya fiksi, baik novel atau drama, harus terjadi pada suatu tempat dan dalam suatu waktu yang terikat pada ruang dan waktu (Sayuti, 2000). Latar fiksi dapat dikategorikan dalam tiga bagian, yakni latar tempat, latar waktu, dan latar sosial.

Latar Tempat

Latar tempat menyangkut deskripsi tempat suatu peristiwa cerita terjadi dan biasanya berkaitan dengan topografis geografis (Sayuti, 2000). Latar tempat bisa terbentuk dari scenary pemandangan yang tergambar dari dekorasi panggung, dari jenis pekerjaaan dan cara-cara hidup atau tradisi budaya yang dijalankan tokoh-tokoh. Latar tempat dalam tarling drama Baridin karya $\mathrm{H}$. Abdul Ajib dapat dilihat dari budaya dan bahasa yang digunakan tokoh yakni bahasa Cirebon menunjuk latar tempat di Cirebon. Sedangkan kondisi topografis geografisnya menggambarkan wilayah pantura Jawabarat, tepatnya wilayah sekitar kotamadya Cirebon. Untuk dapat diidentifikasi selanjutnya latar pada tarling drama Baridin diwujudkan dalam beberapa tempat di setiap adegan yakni:

Pertama, latar di rumah Baridin pada adegan ketiga yang ditandai dengan dialog Baridin dengan mbok Wangsih nomor 20-22, berikut dialognya:

19. BARIDIN:

Baridine durung lekas menggawe ning sawahe mang Bu Nawas

(Baridin belum membajak sawahnya pak Abu Nawas)

20. MBOK WANGSIH:

Kenangapa sira balik maning? (kenapa kamu balik lagi)

21. BARIDIN:

Kenang alangan mbok (ada rintangan mbok)

Pada dialog tersebut, mbok Wangsih menanyakan pada Baridin kenapa balik lagi (pulang ke rumah)?, dan Baridin menjawab kalau ia kena halangan sewaktu akan 
membajak sawah pak Bunawas sehingga ia terpaksa menunda pekerjaannya dan memilih pulang ke rumah. Pada adegan ketujuh juga terjadi di latar tempat rumah Baridin, ini ditandai ketika Baridin menembangkan lagu suka cita, ditemani Gemblung dan kawan Gemblung yang datang menemui Baridin dan mereka merayakan kebahagiaan Baridin yang akan menikah dengan gadis yang bernama Suratminah.

Kedua, latar di rumah Suratminah pada adegan keempat, kelima, keenam, kesembilan, kesepuluh, kesebelas, kedua belas, dan ketiga belas. Adegan keempat merupakan adegan tukang palak diundang bapak Dam ke rumahnya untuk meramal mimpi bapak Dam. Sedangkan adegan kelima-ketujuh adalah adegan kedatangan pelamar (juragan, nelayan, dan mbok Wangsih) untuk melamar Suratminah. Pada adegan kedelapan sampai ketiga belas merupakan adegan klimaks peristiwa keadaan Suratminah saat akan dikemat dan ketika dikemat Jaran guyang oleh Baridin yang terjadi di rumah Suratminah.

Ketiga, latar suasana di jalan desa seperti pertigaan jalan gang yang menuju sawah dan pasar. Ini ditandai pada adegan pertama dan kedua ketika Baridin yang akan ke sawah Bunawas bertemu tidak sengaja dengan Suratminah yang akan pergi ke pasar, yang kemudian dilanjut pada adegan kedua muncul koor tembang teman-teman Suratminah yang turut mengejek Baridin.

Keempat, latar suasana di persawahan pada adegan kedelapan dan kelima belas. Peristiwa yang terjadi pada adegan kedelapan adalah ketika Baridin pergi meninggalkan rumah karena diusir mbok Wangsih, lalu ia menyendiri di sawah sambil menyanyikan tembang maskumambang. Sedangkan adegan kelima belas merupakan catastrophe yakni diakhir cerita, Suratminah dan Baridin meninggal di sawah.
Latar Waktu

Latar waktu mengacu pada saat terjadinya peristiwa dalam plot yang berkaitan dengan masalah historis (Sayuti, 2000). Latar waktu pada drama Baridin dapat diidentifikasi dari serangkaian peristiwa dalam plot yakni; pagi hari pada adegan kesebelas yang ditandai dengan suara ayam jago berkokok dan ramainya suara temanteman Suratminah yang akan membantu panen sawah bapak Dam, dan pada malam hari adegan kesepuluh yang ditandai dengan dentingan jam dinding yang berdenting dua belas kali dan disusul peristiwa Baridin kemat Suratminah yang dibangun dengan suasana mencengkam, dan ini hanya bisa diwujudkan pada malam hari.

Latar Sosial

Latar sosial merupakan lukisan status yang menunjuk hakekat seseorang atau beberapa orang tokoh dalam masyarakat yang ada disekelilingnya (Sayuti, 2000). Latar sosial dalam tarling drama Baridin bisa diidentifikasi dari kolektivitas kostum yang dipakai tokoh-tokohnya. Pertama, dari pakaian Baridin dan mbok Wangsih yang memakai pakaian kumal dan lusuh menidentifikasikan latar sosial kelas bawah. Kedua, pakaian Suratminah yang memakai gaun berhias manik-manis lengkap dengan aksesoris kalung dan bapak Dam yang memakai jas serta blangkon menidentifikasikan latar sosial dari kelas menengah atas.

\section{Makna kemat Jaran guyang}

Tedeuz Kowzan mengatakan bahwa langkah kerja pertama menafsirkan kode dalam teater adalah dengan menentukan unit signifkatif tontonan atau unit semiologik (Sahid, 2012). Unit signifkatif adalah suatu unsur yang berisi semua kode-kode yang dimunculkan secara bersamaan, dan setiap unsur terkecil itu memiliki berbagai kode atau tanda sekaligus. Tanda-tanda dalam teater perlu disusun sedemikian rupa untuk 
menolong dalam memastikan makna (Sahid, 2012). Untuk menyederhanakan proses pemaknaan, digunakan teori tanda dari Ferdinand de Saussure yang mengatakan, bahwa tanda merupakan kesatuan dari dua aspek yang tidak dapat dipisahkan satu sama lain, yakni signifiant (penanda) dan signifie (petanda) (Sahid, 2012).

Adegan kesepuluh merupakan adegan klimaks dari alur dramatik tarling drama Baridin, menceritakan peristiwa laku kemat jaran guyang yang dikidungkan Baridin kepada Suratminah. Kemat Jaran guyang merupakan salah satu jenis jawokan yang berfungsi sebagai mantra agar mendapatkan cinta kasih dari seseorang yang dikemat (Noer, 2015). Berikut makna beradasarkan nilai estetis syair kemat jaran guyang yang dikidungkan Baridin dalam tarling drama Baridin.

Niat ingsun arep pan maca kemat jaran guyang

Dudu ngemat tangga

Dudu ngemat-ngemat wong liwat ning dalan

Sing tek kemat nok Suratminah anakke Bapak Dam

kang ayu, kang gembleng, kang demen pirang-pirang.

Yen lagi turu gagia nglilira

Yen wis nglilir gagia tangia

Yen wis tangi gagia njagong

Yen wis njagong gagia ngadeg

Yen wis ngadeg gagia mlayua brengengea kaya jaran

Kawelasasih Suratminah welasasih ning badan ingsun.

(Niat saya baca kemat jaran guyang

Bukan ngemat tetangga

Bukan ngemat orang lewat dijalan

Yang ku kemat nok Suratminah anaknya bapak Dam

Yang cantik, yang molek, yang disukai banyak orang

Kalau sedang tidur segera bangunlah

Kalau sudah bangun segeralah duduk

Kalau sudah duduk berdirilah

Kalau sudah berdiri larilah kencang seperti jaran
Kasihilah Suratminah agar sayang dan jatuh cinta kepadaku)

Pada larik pertama syair kemat jaran guyang berbunyi "Niat ingsun arep pan maca kemat jaran guyang" (penanda) memiliki rima (ang), dan mempunyai arti secara harafiah dalam bahasa Indonesia (denotatif) adalah "niat saya baca kemat jaran guyang"(petanda). Secara konotatif dilihat dari unsur bunyi, rima, maupun bahasa, larik pertama syair kemat jaran guyang bermakna penegasan dari suatu perbuatan yang dilihat dari awal laku yakni pembacaan niat kemat jaran guyang. Pembacaan niat merupakan syarat yang menggambarkan kejelasan, keseriusan, kekhusukan dari perbuatan yang dilakukan agar mendapat tujuan yang diinginkan misal sesorang yang ingin beribadah sholat diawali dengan pembacaan niat sholat, bukan dengan pembacaan niat yang lain seperti niat puasa, niat bersedekah atau lainnya.

Larik kedua syair kemat jaran guyang berbunyi “Dudu ngemat tangga" (penanda) memiliki rima (a), dan mempunyai arti secara denotatif dalam bahasa Indonesia adalah "bukan mengemat tetangga". Secara konotatif, signifikasi dari signifie (denotatif) adalah maksud tujuan kemat hanya ditujukan bukan pada sembarang orang (tetangga), tetapi kepada orang tertentu. Penegasan kepada orang yang dikemat semakin terlihat pada larik ketiga dan larik keempat. Berikut larik ketiga berbunyi "Dudu ngemat-ngemat wong liwat ning dalan" (penanda) memiliki rima (an), mempunyai arti dalam bahasa Indonesia "bukan mengemat orang lewat di jalan" (petanda), dan larik keempat berbunyi "Sing tek kemat nok Suratminah anakke Bapak Dam" (penanda) memiliki rima (am), dan secara harfiah dalam bahasa Indonesia berarti "yang tak kemat Suratminah anaknya bapak Dam"(petanda). Penegasan siapa orang yang akan dikemat Baridin terlihat pada larik empat yakni Suratminah anaknya Bapak Dam. 
Pada larik kelima berbunyi "kang ayu, kang gembleng, kang demen pirang-pirang" (penanda) memiliki rima (ang) sama dengan rima pertama, mempunyai arti dalam bahasa Indonesia adalah "yang cantik, yang molek, yang disukai banyak orang" (petanda), dan secara konotatif bermakna penggambaran secara fisik, maupun sosial dari sosok orang yang ditujukan dalam pembacaan kemat. Penggambaran sosok tersebut diucapkan selain untuk memperjelas siapa orang yang dikemat, juga sebagai alasan kenapa sosok orang tersebut yang ingin dikemat. Dalam hal ini, Suratminah dimata Baridin adalah sosok perempuan yang dianggap sempurna, karena kecantikannya juga secara sosial adalah perempuan yang diidamkan banyak lelaki.

Pada keseluruhan larik pertama sampai larik kedua, bunyi dari setiap rima pada lariknya tidak terlalu diperhitungkan, tetapi lebih mengandung unsur-unsur puisi daerah yang bertumpu pada rima daerah yakni purwakanti. Unsur purwakanti itu tampak pada larik keenam hingga kesepuluh dengan memainkan kosakata "yen" sebagai purwakanti awal dengan "gagia" sebagai purawakanti tengah secara berulang-ulang.

Secara denotatif, unsur purwakanti dalam kosakata "yen"(penanda) yang dalam bahasa Indonesia berarti "kalau" (petanda). Makna denotatif "kalau" jika dibacakan berulang dan berurutan maka akan mempunyai arti secara konotatif adalah keinginan, pengharapan yang terus diulang dan menggebu-gebu. Sedangkan makna denotatif dari unsur purawakanti dalam kosa kata "gagia" dalam pengertian harfiah dalam kamus bahasa Cirebon artinya adalah segera, dan jika dibacakan berulang-ulang dan berurutan maka akan bermakna segera cepat, atau tidak menunda-nunda. Pemaknaan denotatif dan konotatif tersebut semakin diperkuat dengan ritme kidung yang ritmis dan cepat. Jawokan kemat jaran guyang tersebut dikidungkan dengan ritme yang ritmis dan cepat, diiringi musik instrumen traling pada bagian awal ritme kidung berupa tetabuhan kendang, gitar dan kecrek, disetiap akhir kalimat jawokan diiringi petikan gitar, dan ditabuhi beberapa pukulan kendang serta kecrek diakhir ritme kidung.

Selain bermakna estetis, kidung kemat jaran guyang juga bermakna mistis. Sebagaimana diketahui, Cirebon sebagai bekas kota Padjajaran yang basis religinya adalah Hindu, lalu datang agama Islam yang disebarkan oleh wali sanga telah mengalami singkritisme budaya dan kepercayaan, dan jawokan adalah salah satu wujud singkritisme itu sendiri. Makna mistis ini terwujud dari korelasi antara syair dengan sesuatu yang bersifat ghaib. Hal mistis ini bisa terjadi karena ada semacam sugesti, misal pada purwakanti kidung kemat jaran guyang larik keenam sampai ketujuh untuk sebutan "yen" dan "gagia" yang dibaca berulang dan cepat bisa menciptakan "sesuatu" lain diluar logika bagi sebagian orang yang percaya akan secara tidak sadar "patuh" mengikuti apa yang disebutkan dalam kemat.

Kemat jaran guyang yang dilapalkan Baridin ternyata diwujudkan sebagai jawaban atas kekecewaan dan keputusasaan tokoh. Tokoh Baridin mengalami penurunan moral pada saat dirinya kecewa dan sedih saat diusir mbok Wangsih, ia seperti tidak mempunyai pegangan hidup. Lalu muncul tokoh Gemblung, orang yang memperkenalkan dan memberikan ajian kemat jaran guyang. Sebenarnya Baridin tidak percaya dengan hal-hal mistis termasuk kemat, tapi karena pikirannya buntu akhirnya ia menjalankan kemat jaran guyang. Penurunan moral itu berdampak pada psikologis Baridin, kerelaan ia menjalani syarat puasa pati geni selama empat puluh hari berturut-turut ternyata mengubah jiwa Baridin menjadi pendendam dan menginginkan kesetimpalan dari apa yang sudah dilakukannya yakni, agar Suratminah tergila-gila padanya dan menjadi gila. 


\section{Simpulan}

Tarling drama Baridin karya $\mathrm{H}$. Abdul Ajib produksi Kurnia Nada group memiliki unsur-unsur pembentuk unit semiologik. Setiap unit semiologik adalah suatu irisan yang berisi semua tanda-tanda yang dimensi secara simultan. Ericka Fischer Lichte telah mengindentifikasi sejumlah sistem tanda utama teater menjadi 14 sistem tanda yang mencangkup: bunyi, musik, bahasa, paralinguistik, mimik, gesture, proksemik (ruang), konsep panggung, dekorasi panggung, masker, rambut, kostum, prop, dan tata cahaya. Tanda-tanda dalam teater perlu disusun sedemikian rupa untuk menolong dalam memastikan makna secara denotatif dan konotatif.

Analisis ko-tekstual memusatkan pada keteraturan-keteratuan "internal" teks pertunjukan dengan sifat-sifat material dan formalnya (antara lain heterogenitas atau keberagaman ekspresifnya, multifitas atau banyaknya kode-kode, durasi yang pendek, atau sifat yang tidak bisa diulang) dan levellevel struktur tekstual (kode - kode dan struktur tekstual). Struktur mencangkup bentuk dan isi, sejauh mempunyai fungsi estetis. Struktur bagian teater tradisi tarling drama Baridin tersusun dari; pertama, unsur temanya yakni dendam atas cinta yang ditolak, kedua, dialognya yang beragam seperti dialog naratif, dialog tembang parikan dan wangsalan, serta dialog kidung jawokan, keempat, alurnya tersusun atas lima belas adegan dimana adagen pertama menunjukan pengenalan tokoh dan peritiwa, lalu konflik yang terjadi pada adegan enam ketika mbok Wangsih dihina sampai pada titik klimaksnya di adegan sepuluh ketika Baridin mengemat Suratminah, dan adegan ditutup dengan meninggalnya tokoh Suratminah dan Baridin, kelima, penokohan tokoh terbagi menjadi tokoh sentral yakni Baridin dan tokoh periferal yakni Suratminah, mbok Wangsih, bapak Dam, Gemblung dan tukang palak, ketiga, penokohan, dan kelima, latar tarling drama Baridin menunjukan latar masyarakat pinggiran pantai utara dan peristiwa tersebut berlangsung di masa menjelang panen padi.

Adegan kemat jaran guyang pada bagian teater tradisi tarling drama Baridin memiliki makna estesis dan mistis. Makna estetis itu hadir dari sistem tanda bahasa dan bunyi pada syairnya, dimana ada larik syair kemat jaran guyang yang berbentuk purwakanti yakni pengulangan bunyi di awal dan di tengah larik. Sedangkan makna mistis yang hadir dalam adegan ini merupakan korelasi antara syair dengan sesuatu yang bersifat ghaib, yang hanya dirasakan sebagai sesuatu yang kasat mata. Hal ini juga semacam sugesti, bahwa bunyi "yen" dan "gagia" pada kidung jawokan kemat jaran guyang seolah menciptakan energi yang dipercaya sebagian orang akan membuat kepatuhan serta ketundukan bagi orang yang dikemat.

Struktur pertunjukan bagian teater tradisi tarling drama Baridin secara bentuk dan isi memiliki kerumitan tersendiri dari penentuan unsur-unsur pembentuk struktur dramatiknya yang memerlukan telaah langsung dengan teks pertunjukannya, penentuan makna dari setiap kode yang dihadirkan dalam setiap unsur-unsurnya memerlukan kedekatan empiris dan intelektual tersendiri guna mendapatkan makna denotasi dan makna konotasi.

\section{Daftar Pustaka}

Bandem, I. M., \& Sal, M. (2000). Teater Daerah Indonesia. Yogyakarta: Kanisius.

Barba, E. (1991). A Dictionary Of Theatre Antropology The Secret Art Of The Performer. London: Routledge.

Marinis, M. (1993). The Semiotics of Performance. Bloomington: Indiana University Press. Terjemahan Nur Sahid. 2013. Yogyakarta: Institut Seni Indonesia. 
Sunaryo, U. (2016). Abdul Adjib dan Tarling Putra Sangkala. Cirebon: Padepokan Abdul Ajib.

Noer, N. M. (2015). Suluk dan Jawokan Ekspresi Sastra dan Mistis Masyarakat Cerbon dan Dermayu. Cirebon: Dinas Pariwisata dan Kebudayaan prov. Jawa Barat.

Sahid, N. (2012). Semiotika Teater Teori dan Penerapannya. Yogyakarta: Badan Penerbit ISI Yogyakarta.

Satoto, S. (2012). Analisis Drama dan Teater Jilid 2. Yogyakarta: Penerbit Ombak.

Sayuti, S., A. (2000). Berkenalan dengan Prosa Fiksi. Yogyakarta: Gama Media.

Stanton, R. (2012). An Introduction to Fiction. London: Holt, Rinehart and Winston. (Sugihatuti \& Al Irsyad, R.A. Trans.). Yogyakarta: Pustaka Pelajar.

Welek, R., \& Waren, A. (2014). Theory of Literature. Terjemahan Melani Budianta. Cetakan kelima. Jakarta: PT Gramedia Pustaka Pusat. 